\title{
Full mouth rehabilitation of the intellectually disabled patient with collapsed bite using partial removable dental prosthesis: a case report
}

\author{
Min-Ji Kim, Hong-So Yang, Sang-Won Park, Hyun-Pil Lim, Kwi-dug Yun, Chan Park* \\ Department of Prosthodontics, School of Dentistry, Chonnam National University, Gwangju, Republic of Korea
}

Intellectual disability is an imperfect disorder in which mental development is permanently retarded and development of intellectual ability is inadequate. Having intellectual disabilities makes it difficult to handle their own work and adapt to social life. For this reason, it is difficult to hygienically manage the patient's oral condition, multiple caries are easily observed, and the periodontal disease incidence rate is high. The patient in this case is a 33-year-old female with a mental retardation first grade who had a problem with meals. In first visit, Patients had decreased occlusal vertical dimension and posterior bite collapse due to periodontitis and multiple caries. This case reports a satisfactory functional and esthetic results by reconstructing occlusion using partial removable dental prosthesis. (J Dent Rehabil Appl Sci 2017;33(3):216-22)

Key words: intellectual disability; bite collapse

\section{서론}

지적장애란 정신 발육이 지체되어 지적 능력의 발달이 불완전하고 사회생활에의 적응이 상당히 곤란한 상태로 지능지수에 따라 세 등급으로 나뉜다. 지적장애 1 급의 경 우 지능지수가 35 미만으로 일상생활과 사회생활에 적응 하는 것이 현저하게 곤란하여 일생 동안 다른 사람의 보 호가 필요하다. 지적장애인은 단순히 지적 능력이 떨어지 는 것뿐만 아니라 운동, 정서, 성격 등 전반적으로 장애를 가진다. 장애의 경중에 따라 나타나는 특성에 차이가 있 으나 대부분 언어발달에 문제가 있고 사회성 발달에 문 제가 있다. 또한 운동기능의 발달문제가 있어 수조작에 어려움을 겪기도 한다. 그렇기 때문에 환자 스스로 구강 상태를 위생적으로 관리하는 것이 쉽지 않아 다발적 우 식이 쉽게 관찰되며 치주질환 이환율이 높다. ${ }^{1}$

*Correspondence to: Chan Park

Associate Professor, Department of Prosthodontics, School of Dentistry, Chonnam National University, 33, Yongbong-ro, Buk-gu, Gwangju, 61186, Republic of Korea

Tel: +82-62-530-5638, Fax: +82-62-530-5639, E-mail: upgradepc@hanmail.net Received: July 17, 2017/Last Revision: July 21, 2017/Accepted: July 22, 2017
본 증례는 지적장애를 가진 환자에서 치주염과 다발적 인 우식으로 인해 붕괴된 교합을 가철성 국소의치로 교 합을 재구성하여 심미와 기능을 회복시킨 증례이다.

\section{증례보고}

환자는 지적장애 1 급의 33 세 여환으로 치아와 잇몸 이 좋지 않아 식사에 어려움이 있다는 주소로 내원하였 다. 환자는 문장을 만들어 의사표현을 하는 데에 어려움 이 있었으나 간단한 단어로 의사는 표현할 수 있었으며 치료 시 협조도는 적절하였다. 환자의 구내 검사 결과 전 반적으로 치은이 붓고 출혈이 있었으며 다발적인 우식 이 관찰되었다(Fig. 1). 또한 구치부 지지 상실과 치주염 및 우식으로 인해 치아 이동이 일어나 전치부, 구치부 과 교합으로 교합이 붕괴되어 있음을 확인하였다. 잔존치중

Copyright@ 2017 The Korean Academy of Stomatognathic Function and Occlusion. (c) It is identical to Creative Commons Non-Commercial License. 

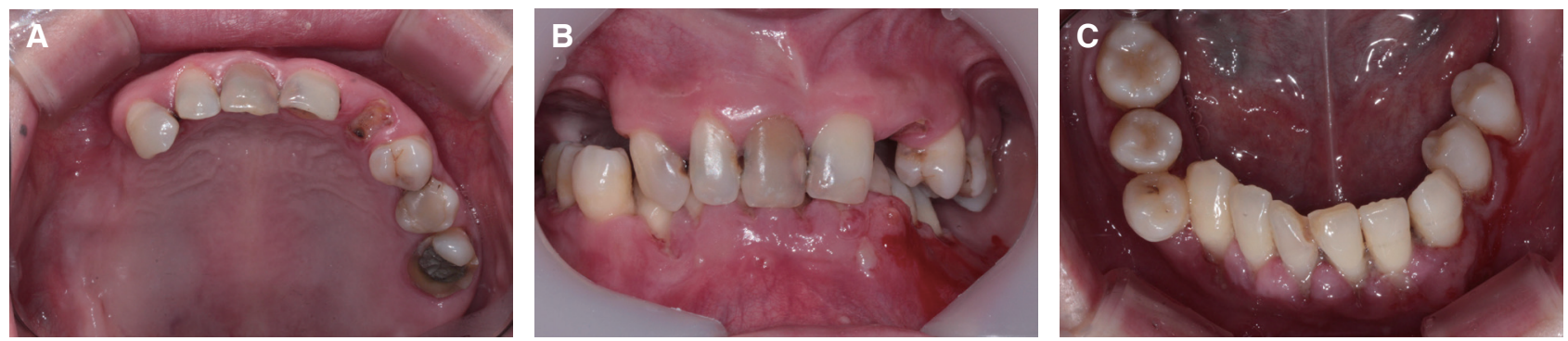

Fig. 1. Initial intraoral photographs. (A) Maxillary occlusal view, (B) Frontal view, (C) Mandibular occlusal view.

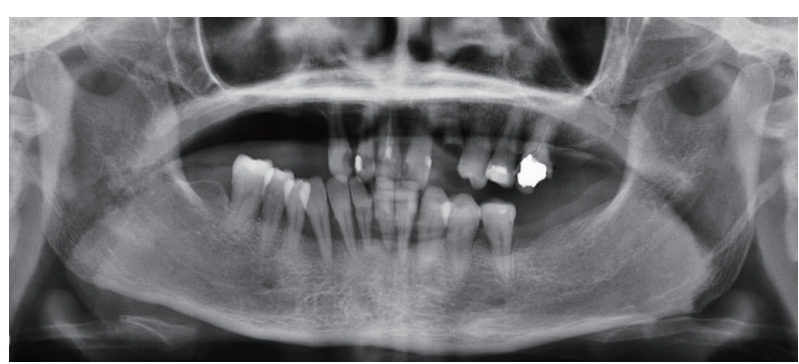

Fig. 2. Initial panoramic radiography.

\#23,31,32,41,42,43,44는 치아가 우식과 치주질환으로 인해 예후가 불량하였으나 그 외 방사선 분석 결과 특이 한 소견은 보이지 않았다(Fig. 2).

교합수직고경 분석을 위해 Willis method로 안모를 분석한 결과 짧은 하안모를 보였으며, interocclusal rest space는 약 $7 \mathrm{~mm}$, 's' 발음 시 전치부간 거리는 $5-6 \mathrm{~mm}$, intervestibular distance는 $29 \mathrm{~mm}$ 로 감소된 수직고경의 회복과 함께 교합평면을 재구성하기로 하였다. 환자에게 치료방법으로 임플란트를 이용한 고정성 보철 이나 가철 성 보철 또는 자연치를 이용한 가철성 보철 치료에 대해 설명하고 상담 진행하였으나 경제적인 문제와 잔존 치조 골의 폭경이 좁은 해부학적 구조로 인해 임플란트보다는 자연치를 이용한 가철성 국소의치 제작으로 치료계획을 결정하였다. 그러나 환자의 특성상 치료에 앞서 가철성
보철물 사용능력에 대한 평가가 필요하였다.

예후가 불량한 치아들을 발거하고 치주치료 및 치아우 식증 치료를 시행한 후 치아 삭제를 하였다. 제작한 진단 왁스업 모형을 이용해 중심위상태에서 임시보철물을 제 작하였다(Fig. 3). 환자는 수조작이 서툴긴 하였으나 임 시의치 사용에 무리가 없었다. 임시보철물 상태에서 3 개 월 간 적응능력을 판단하였다. 3 개월 동안 악관절 문제나 근신경계 문제는 보이지 않았으나 적응력이 떨어지는 환 자의 특성상 임시의치를 제거한 상태에서 불안정한 교합 상태를 보였다. 3 개월 추가적인 적응 기간을 두어 총 6 개 월이 지나서야 환자는 안정된 교합을 보였다. 또한 심미 적, 기능적으로도 환자, 보호자 모두 만족하였기에 최종 보철물을 제작하기로 하였다.

가철성 국소의치의 지대치인 \#11,12,13,21,24,25,26, $33,34,35,45,46$ 을 polyvinyl siloxane 인상재(Honigum, DMG, Hamburg, Germany)로 인상채득하였다(Fig. 4). 제작된 써베이드 크라운을 치아에 시적 후 레진 접착제 (Rely X luting cement, 3M ESPE, St. Paul, USA)를 사 용하여 접착하였다(Fig. 5).

개인트레이의 제작을 위해 상, 하악 예비인상을 채득 하였다. 연구모형에서 개인트레이를 제작하여 변연형성 후 폴리설파이드 인상재(Permlastic, Kerr Manufacturing $\mathrm{co}$, Romulus, USA)를 사용하여 최종 인상채득하였다 (Fig. 6). 하악의 경우 전방부 전정과 좌측 구치부 전정이
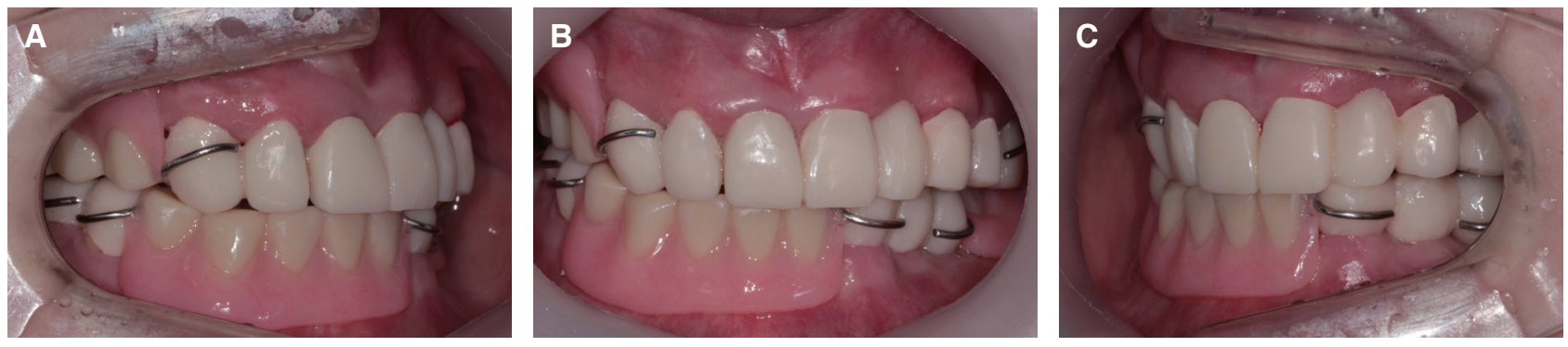

Fig. 3. Provisional prosthesis. (A) Lateral view (right), (B) Frontal view, (C) Lateral view (left). 

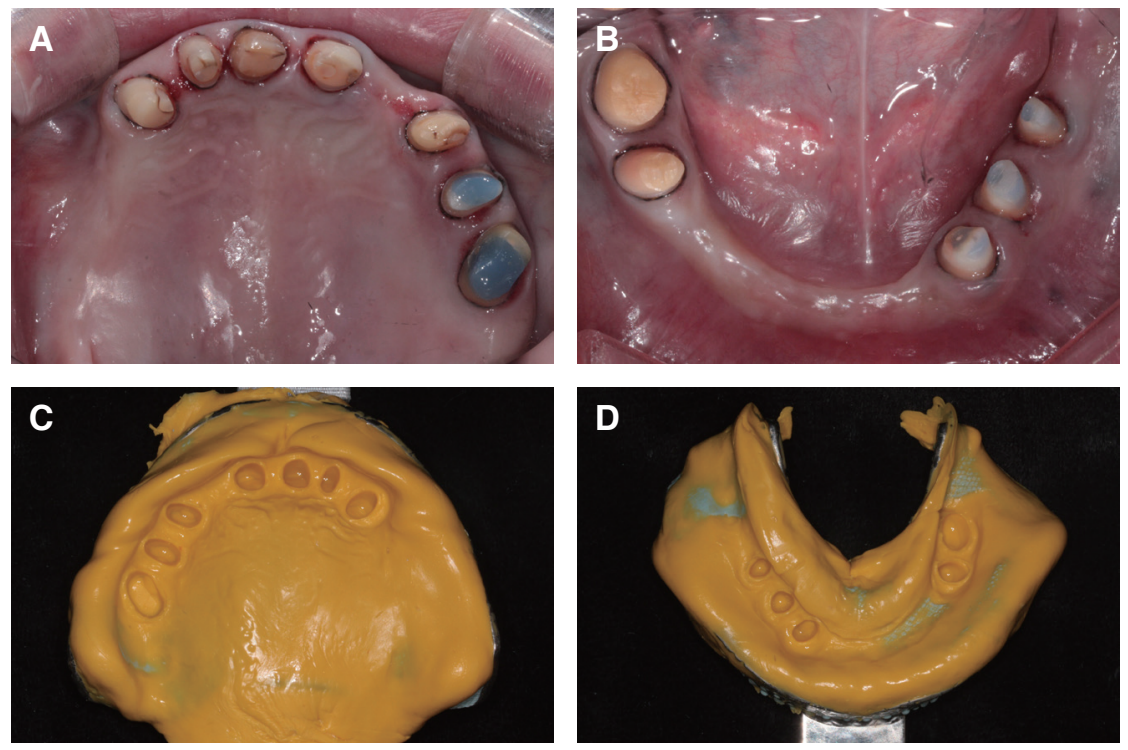

Fig. 4. Teeth preparation and final impression. (A) Maxillary teeth, (B) Mandibular teeth, (C) Final impression of Maxilla, (D) Final impression of Mandible.
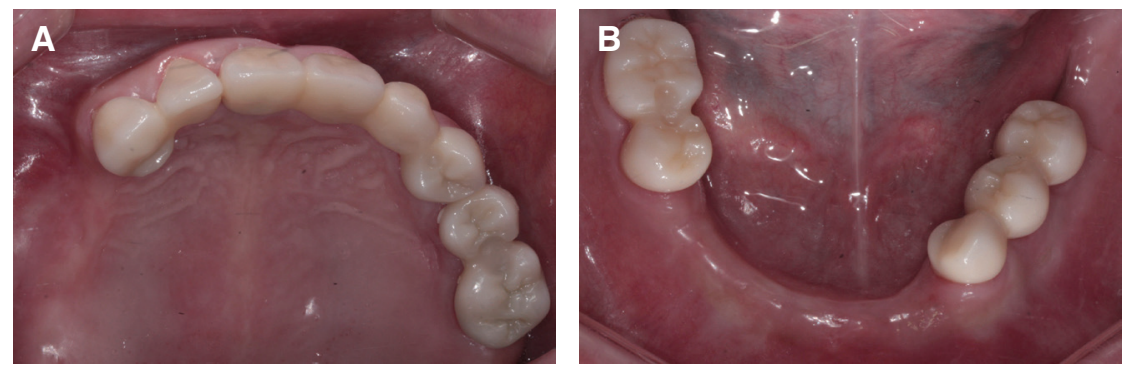

Fig. 5. Definitive restoration. (A) Surveyed crown on maxilla, (B) Surveyed crown on mandible.
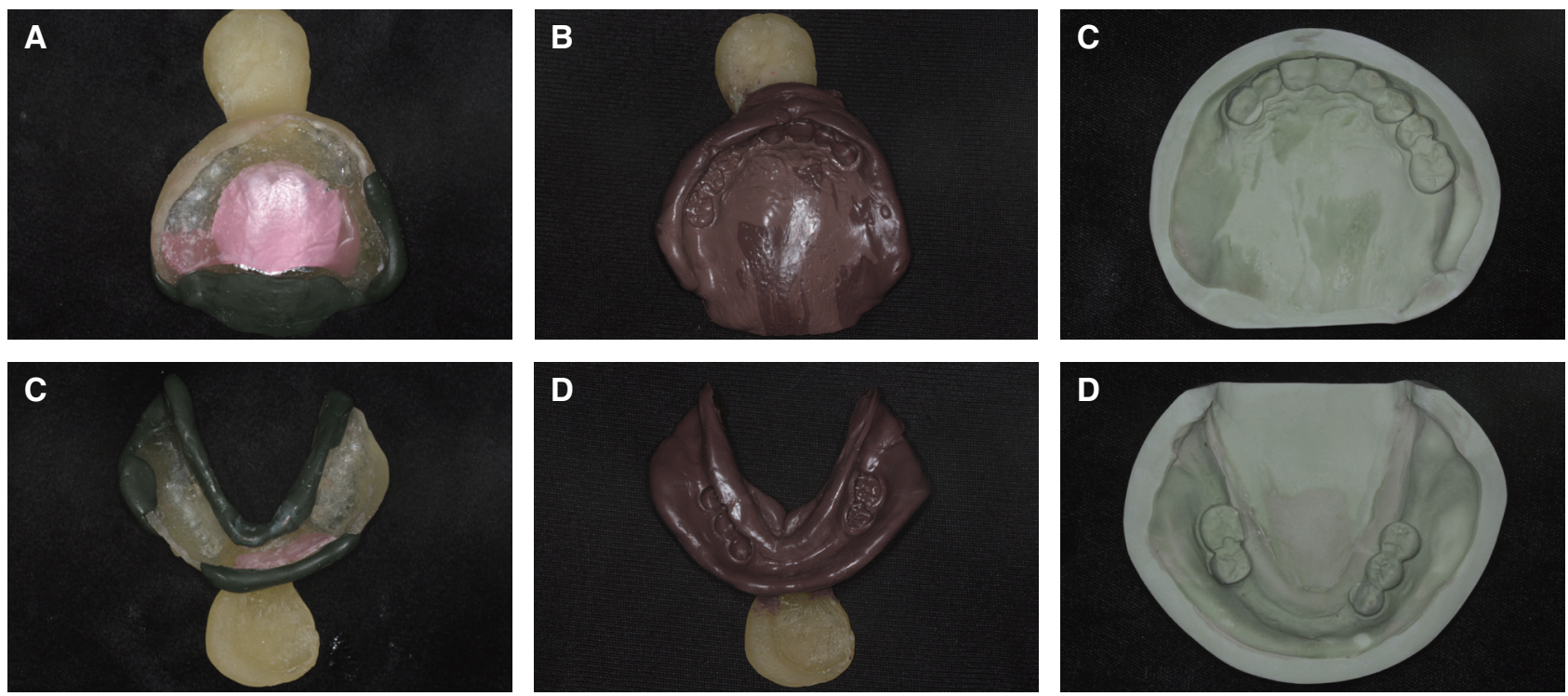

Fig. 6. Bordermolding and final impression. (A) Bordermolding for maxillary denture, (B) Final impression of maxilla, (C) Master cast of maxilla, (D) Bordermolding for mandibular denture, (E) Final impression of mandible, (F) Master cast of mandible. 
얕고 소대가 높아 설측 판 이용하여 금속구조물을 제작 하였다. 또한 금속구조물 제작 시 환자의 의치 탈착을 용 이하게 하기 위해 직접유지장치는 환상형클래스프로 디 자인 하였다(Fig. 7). 교합제를 평균적인 규격에 따라 제 작하고 임시의치의 상하악 악간관계를 이용해 수직위, 수평위를 교합기에 이전하였다(Fig. 8). 인공치아를 배열 하여 군기능 교합을 부여하였다. 납의치를 구강 내에 시
적 하였고, 환자와 보호자는 치아 형태 및 배열에 만족하 였기에 온성을 시행하였다(Fig. 9). 그 후 기공실 재부착, 임상적 재부착을 통해 기공과정에서 생긴 교합오차를 수 정하여 군기능 교합을 부여하였고 구강 내에 장착하였다 (Fig. 10). 술 후 방사선 영상에서 특이한 병적 변화는 관 찰되지 않았으며 치료 이후 6개월 관찰 결과 기능적, 심 미적으로 만족할 만한 결과를 얻었다(Fig. 11).
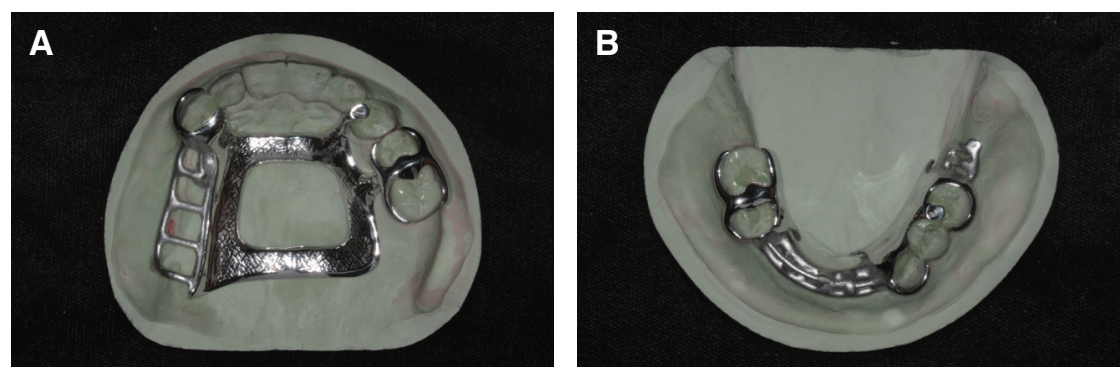

Fig. 7. Metal framework. (A) Metal framework of maxilla, (B) Metal framework of mandible.
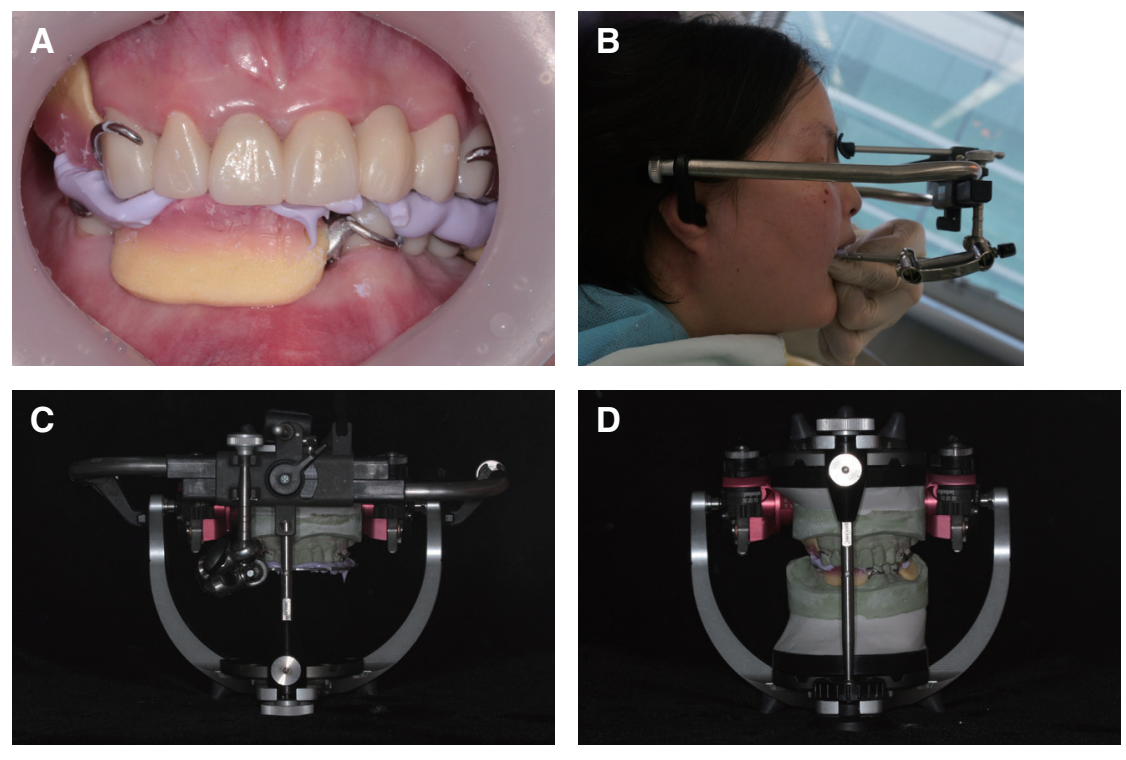

Fig. 8. (A) Maxillomandibular relationship registration, (B) Facebow transfer, (C, D) Mounting procedure to semiadjustable articulator.
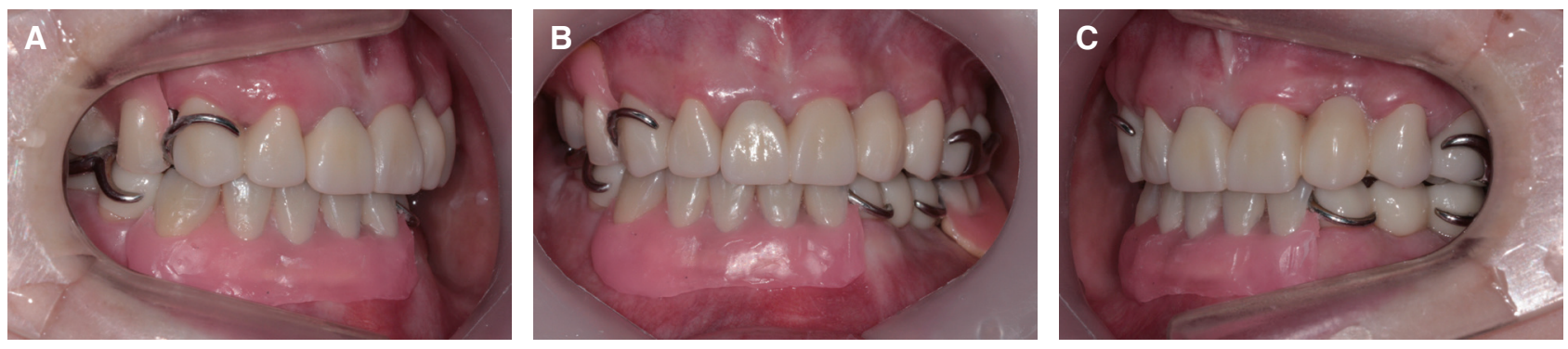

Fig. 9. Wax denture try-in. (A) Lateral view (right), (B) Frontal view, (C) Lateral view (left). 

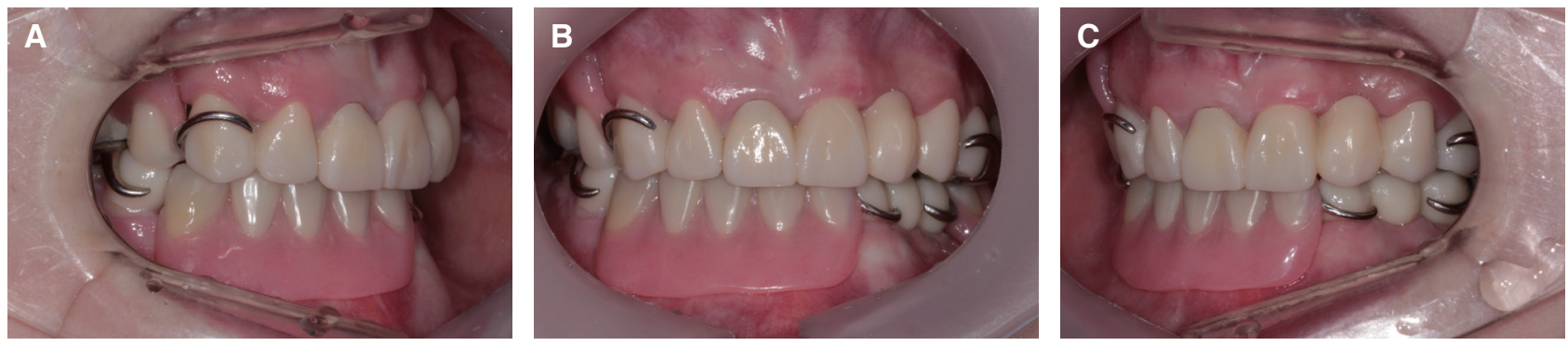

Fig. 10. Definitive denture. (A) Lateral view (right), (B) Frontal view, (C) Lateral view (left).
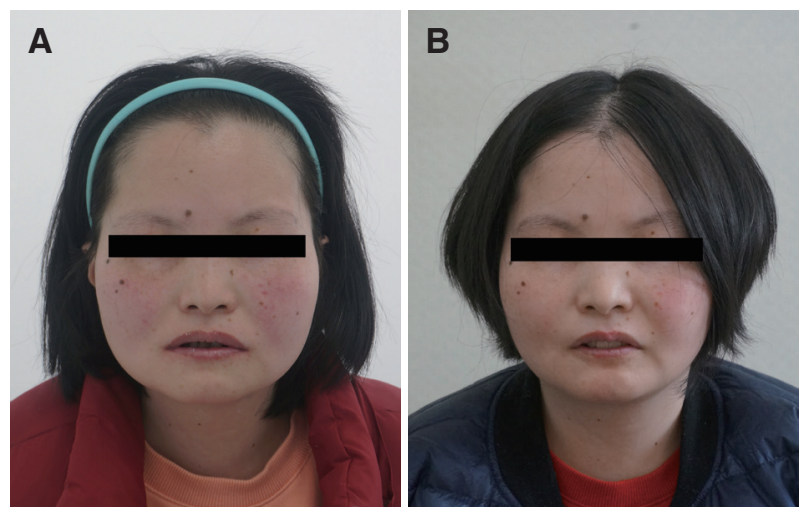

Fig. 11. Patient's profile. (A) Profile of first visit, (B) Profile of after definitive denture delivery.

\section{고찰}

본 증례에서는 지적장애를 가지며 교합이 붕괴된 환자 에서 상하악 가철성 국소의치를 이용하여 기능적, 심미적 으로 만족스러운 결과를 얻었다.

환자가 지적장애를 가지고 있었기 때문에 치료에 앞서 환자의 특성을 파악하고 치료계획을 결정하는 것이 우선 이였다. 본 증례의 환자는 구강위생지수가 낮고 다발성 우식이 존재하며 치은염, 치주염이 존재하는 지적장애인 의 전형적인 구강특성을 보이고 있었다. ${ }^{1,2}$ Shifman에 따 르면 수직교합고경이 감소되어 있고 전치부, 구치부 과 교합, 구치부 지지가 상실되었을 때 교합붕괴로 진단할 수 있다고 하였다. ${ }^{3}$ 그 원인으로는 치아결손, 치주염, 우 식이 대표적인데 본 증례의 환자에서도 이와 같은 원인 이 있었기에 교합붕괴가 나타났을 것이라 추측하였다
지적장애인의 치과치료시 치아가 결손되었을 경우 유 지와 관리 문제로 인해 임플란트를 이용한 고정성 보철 치료가 우선시 된다. ${ }^{4}$ 하지만 치아 결손이 다수로 존재하 고 경제적인 문제 및 임플란트 시술에 어려움이 있는 해 부학적 구조를 가졌을 경우 가철성 국소의치로 치과치료 를 시행할 수 있다. Phadraig의 코호트 연구에 따르면 가 철성 의치가 필요한 지적장애인 중 의치 제작을 한 장애 인 수는 많지 않지만 의치를 제작했을 경우 약 $82.6 \%$ 에 해당하는 장애인이 의치를 잘 사용하고 있었다고 하였 다. ${ }^{5}$

가철성 의치 제작을 위한 본 증례의 환자는 지적장애 1 급으로 의사표현이 자유롭지 못하였으며 수조작이 서툴 고 적응력이 떨어지는 특성을 보였다. ${ }^{6,7}$ 그러므로 치료 전 환자의 적응을 위해 탈감작을 동반한 여러 단계가 필 요했으며 임시의치 과정에서는 오랜기간 동안 환자가 의 치 사용능력에 대한 평가도 필요하였다.

지적 장애 환자에서 중요한 것은 보철 후 유지관리이 다. 지적 장애 환자의 운동기능이 떨어지는 면을 고려하 여 전동칫솔을 이용하게 하거나 사용이 용이하도록 손잡 이가 변형된 칫솔을 이용하게 하여 구강 위생 효율을 높 일 수 있다. 또한 지적 장애 환자는 단기기억력 보다는 장 기기억력이 좋으므로 반복적인 학습을 통해 교육이 가능 하다. 특히 본 증례의 환자는 가철성 국소의치를 사용하 였기 때문에 구강내뿐만 아니라 의치를 탈거하여 세척하 는 방법에 대한 교육이 필요했다. 그러므로 환자의 구강 위생 관리 방법에 대한 습득을 위해 내원 시마다 반복적 이고 장시간의 구강 위생 교육을 시행하고 다음 내원 시 교욱의 효과가 있었는지 확인하였다. 교육 시행 후 계속 적인 구강 위생 관리를 위해서는 병원 내 구강 위생 교육 을 바탕으로 가정 내 구강 위생 관리를 지속적으로 시행 하는 것은 중요할 것이다. ${ }^{8}$ 


\section{결론}

장기간의 적응 기간을 통해 제작된 최종 의치는 이상적 인 교합 평면과 안정적인 교합 접촉을 이룰 수 있게 하였 다. 현재 환자와 보호자는 기능적, 심미적으로 크게 만족 하고 있다. 지적장애를 가진 환자이기에 더 지속적인 검 진을 통한 유지관리가 필요할 것이다.

\section{ORCID}

Min-Ji Kim https://orcid.org/0000-0002-3241-5214

Hong-so Yang https://orcid.org/0000-0002-9138-4817

Sang-won Park https://orcid.org/0000-0002-9376-9104

Hyun-pil Lim https://orcid.org/0000-0001-5586-1404

Kwi-dug Yun https://orcid.org/0000-0002-2965-3967

Chan-Park https://orcid.org/0000-0001-5729-5127

\section{References}

1. Chang J, Lee JH, Son HH, Kim HY. Caries risk profile of Korean dental patients with severe intellectual disabilities. Spec Care Dentist 2014;34:2017.

2. Anders PL, Davis EL. Oral health of patients with intellectual disabilities: a systematic review. Spec Care Dentist 2010;30:110-7.
3. Shifman A, Laufer BZ, Chweidan H. Posterior bite collapse-revisited. J Oral Rehabil 1998;25:376-85.

4. Stiefel DJ. Dental care considerations for disabled adults. Spec Care Dentist 2002;22:26S-39S.

5. Oczakir C, Balmer S, Mericske-Stern R. Implantprosthodontic treatment for special care patients: a case series study. Int J Prosthodont 2005;18:383-9.

6. Schalock RL, Borthwick-Duffy SA, Bradley VJ, Buntinx WHE, Coulter DL, Craig EM, Gomez SC, Lachapelle Y, Luckasson R, Reeve A, Shogren KA, Snell ME, Spreat S, Tassé MJ, Thompson JR, Verdugo-Alonso MA, Wehmeyer ML, Yeager MH. Intellectual disability: definition, classification, and systems of supports. 11th ed. Washington DC; American Association on Intellectual and Developmental Disabilities; 2010.

7. Mac Giolla Phadraig C, Nunn J, Carroll R, McCarron $\mathrm{M}, \mathrm{McC}$ allion P. Why do edentulous adults with intellectual disabilities not wear dentures? Wave 2 of the IDS TILDA cohort study. J Prosthodont Res 2017;61:61-6.

8. A position paper from the Academy of Dentistry for Persons with Disabilities. Preservation of quality oral health care services for people with developmental disabilities. Spec Care Dentist 1998;18:1802. 


\section{교합이 붕괴된 지적장애 환자의 국소의치 수복증례}

\section{김민지, 양홍서, 박상원, 임현필, 윤귀덕, 박찬*}

전남대학교 치의학전문대학원 보철학교실

지적장애는 정신 발육이 항구적으로 지체 되어 지적 능력의 발달이 불충분하고 불완전한 장애이며, 지적장애를 가지면 자신의 일을 처리하는 것과 사회생활에의 적응이 상당히 곤란하다. 그렇기 때문에 환자 스스로 구강상태를 위생적으로 관리하는 것이 쉽지 않아 다발적 우식이 쉽게 관찰되며 치주질환 이환율이 높다. 본 증례의 환자는 지적장애 1 급을 판정 받은 33세 여환으로 치아 및 치주 건강이 좋지 않아 식사에 어려움이 있다는 주소로 내원하였다. 초진 구내 검사 시 환자 는 치주염과 다발성 우식으로 수직고경이 감소되고 구치부 교합이 붕괴되어 있었다. 이를 가철성 국소의치 이용하여 교 합을 재구성함으로써 심미적, 기능적으로 만족할 만한 결과를 얻었기에 보고하는 바이다.

(구강회복응용과학지 2017;33(3): 216-22)

주요어: 지적장애; 교합붕괴 